\title{
https://doi.org/10.48009/2_iis_2006_105-109 \\ MICROFINANCE IN ACTION: \\ A BUSINESS PROCESS ANALYSIS OF AN OPERATION IN NICARAGUA
}

\author{
Julio Martinez, Fairfield University,07_jmartinez3@stagweb.fairfield.edu \\ Winston Tellis, Fairfield University, Winston@mail.fairfield.edu
}

\begin{abstract}
This paper is a business process analysis of an existing and successful microfinance institution in Nicaragua. The authors visited the main office and branch offices to determine the data flow and process relationships between the main office and the branches. For U.S. based organizations, the cultural differences and resource constraints could be informative. As globalization expands, the need to prepare students for assignments in developing countries is one of the goals of this project.
\end{abstract}

Keywords: Business Process, Database, Data Flow, Nicaragua, Developing Country.

\section{INTRODUCTION}

The Local Development Fund [FDL) was formally created in May 5, 1997 as a non-profit organization, and the National Assembly approved its legal status nearly a year later. However, it initially began its financial activities in 1993 as part of Nitlapán, the Research and Development institution of Universidad CentroAmericana [UCA) located in Managua, Nicaragua. Its mission statement follows: "The Local Development Fund [FDL) is a micro-financing institution specializing in financial services, mainly to the rural sector. The target sector for the credit services includes micro, small, and medium-sized businesses of production, commerce and services that are economically viable but have no access to the formal banking sector. FDL also works in urban contexts, which allows it to diversify the credit risk and financial flow."[1]

Since it was founded in 1990, Nitlapán's primary objective has been to find effective methods to guarantee the sustainability and independence of local rural development programs. By 1992, it began managing circulating funds to help address problems that were primarily occurring in the rural sector [2]. In 1993, it began its second project by creating the Local Development Bank that was structured to finance to rural producers. The Local Development Bank was supported by a self-administration model and was governed by local organizations cooperating with one another.
Between 1994 and 1996 the program enforced administrative control over local banks in an effort to prevent the abuse of power, encourage accountability and regain the lenders' confidence. However, the new changes did not contribute too much improvement for a couple of reasons: 1) Local directors refused to abide by the credit rules and policies and 2) the expansion of credit services was very limited [2]. In addition, the increasing lack of liquidity in the rural sector contributed to the closings of the some regulated banks. As a result, Nitlapán decided to organize a completely new local institution that would have a new administration.

By 1997, the new model's first strategic plan got underway with the launching of the Local Development Fund. It entailed conducting a process of specialized financial services with a strategy oriented to seeking sustainability and a legal separation from Nitlapán. The first plan was executed between 1998 and 2002. During its second strategic plan between 2003 and 2007, the program plans to obtain long-term credit lines with appropriate interest rates that will allow it to offer investment credits [2]. It hopes to meet its objective of providing financial assistance that will support the capitalization of small and medium rural businesses.

\section{Staffing}

FDL currently operates through twelve branches and sixteen satellite offices which are located throughout the country. Since 2002, the staff has grown approximately $13 \%$ each year. As of December 2005, the staff was composed of 351 people [2].

Table 1. Increases in FDL Staff

\begin{tabular}{|l|l|l|l|l|}
\hline Staff & $\mathbf{1 2 / 3 1 / 0 2}$ & $\mathbf{1 2 / 2 1 / 0 3}$ & $\mathbf{1 2 / 3 1 / 0 3}$ & $\mathbf{1 2 / 3 1 / 0 5}$ \\
\hline Total & 237 & 286 & 324 & 351 \\
\hline $\begin{array}{l}\text { Credit } \\
\text { Officers }\end{array}$ & 74 & 90 & 110 & 124 \\
\hline Others & 163 & 196 & 214 & 227 \\
\hline
\end{tabular}




\section{Credit Officer}

Credit officers account for almost half of the FDL entire staff. Under the supervision of a branch director, credit officers are the most active members at FDL. FDL gives each credit officer a motorcycle and computer to complete the daily tasks. Credit officers promote and market FDL's financial services to the local citizens. They also visit existing clients, sometimes at the client's home, regarding the loan. They also process new credit requests [4].

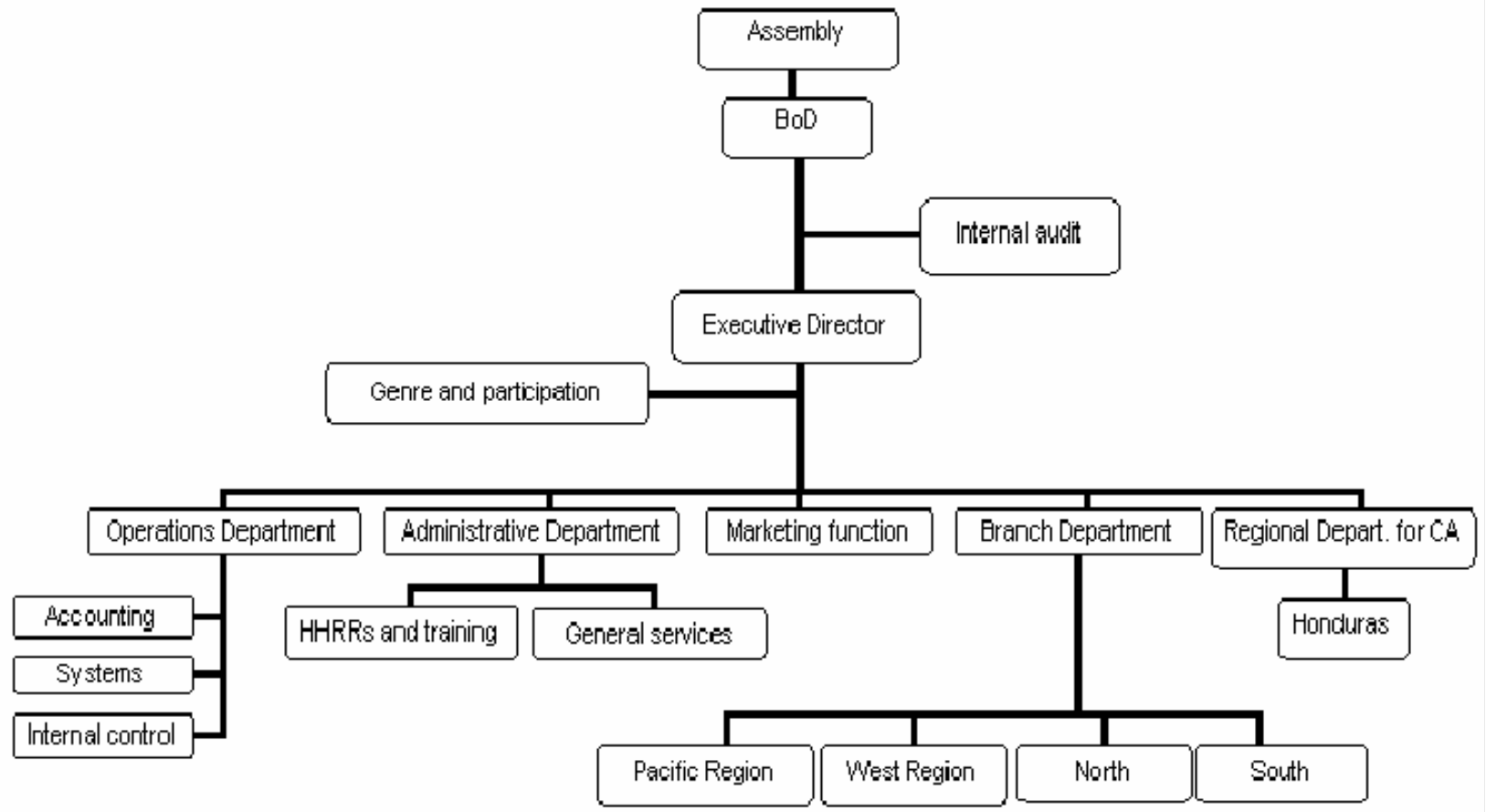

Figure 1. Organization Chart of FDL [2]

Table 2. Increases in FDL Clients [2]

\begin{tabular}{|l|l|l|l|}
\hline Clients & $\mathbf{1 2 / 3 1 / 0 2}$ & $\mathbf{1 2 / 3 1 / 0 3}$ & $\mathbf{1 2 / 3 1 / 0 4}$ \\
\hline Number of active borrowers & 21,306 & 25,106 & 33,676 \\
\hline Average loan balance per borrower & $\$ 587.00$ & $\$ 659.00$ & $\$ 666.00$ \\
\hline Woman borrower & $51.8 \%$ & $51.0 \%$ & $56.0 \%$ \\
\hline Male borrower & $48.2 \%$ & $49.0 \%$ & $44.0 \%$ \\
\hline
\end{tabular}

FDL provides their clients financial services through individual and group lending methodology. Only clients with well established credit history are able to receive individual loans. Besides financial services, FDL also provides their clients with training and technical assistance. In agreement with Nitlapán, FDL provides training and assistance to small and medium businesses and agricultural producers. In 2004, FDL provided training for 1,972 small and medium urban and rural businesses. The training included Basic Accounting, Marketing, Finance and other business related courses [2]. 
Use Case for the Allocation of a Normal Individual Credit [4]

Primary Actor: Client

Scope: Microfinance Bank

Level: Summary

Stakeholders and Interests:

Client- wants to take out a loan

Credit Officer- wants to verify that client is worthy of credit approval

Office Manager- to see that all guidelines are followed

Preconditions: Money is needed to run their business

Trigger: Client initiates credit request

Minimal Guarantee: Client will know whether the credit request has been approved or declined

Success Guarantee: Client has been granted total amount of credit requested

Use Case for the Allocation of an Urban Solidarity Credit [4]

Primary Actor: Client

Scope: Microfinance Bank

Level: Summary

Stakeholders and Interests:

Client- wants to take out a loan

Guarantor- to assure clients in their group make their payments on time

Credit Officer- wants to verify that client is worthy of credit approval

Office Manager- to see that all guidelines are followed

Preconditions: Money is needed to run their business

Trigger: Client initiates credit request

Minimal Guarantee: Client will know whether the credit request has been approved or declined

Success Guarantee: Client has been granted total amount of credit requested. Group agrees on terms and conditions and signs the contract
Use Case for the Allocation of a Rural Solidarity Credit

Primary Actor: Client

Scope: Microfinance Bank

Level: Summary

Stakeholders and Interests:

Client- wants to take out a loan

Guarantor- to assure clients in their group make their payments on time

Credit Officer- wants to verify that client is worthy of credit approval

Office Manager- to see that all guidelines are followed

Preconditions: Money is needed to run their business

Trigger: Client initiates credit request

Minimal Guarantee: Client will know whether the credit request has been approved or declined

Success Guarantee: Client has been granted total amount of credit requested. Group agrees on terms and conditions and signs the contract

\section{Systems}

After a client completes a credit request application, the credit official then determines how much credit should be approved. If the client is new, the credit officer must first obtain a credit history for that person before making any computations [4]. They could obtain the credit report of any new client through www.siuriesgo.com.ni, a website that records any loan activity in Nicaragua. After the credit report has been obtained, the credit officer uses an Excel Worksheet, and the client's information provided in the application, to determine the total amount for which he or she is qualified. After the loan amount is determined, the credit officer inputs all of the client's information to a software program MeraKERP [3]. MeraKERP is a management information system with a platform that manages SQL server databases integrated with accountancy. The system also has the capability to send data from one branch to another directly through e-mail. Branches with satellites receive their data from satellite offices through floppy discs. Each month, every FDL branch sends portfolio and accountancy updates to the headquarters. Each client's information and other financial data are saved and secured at the headquarters in Managua [4]. 


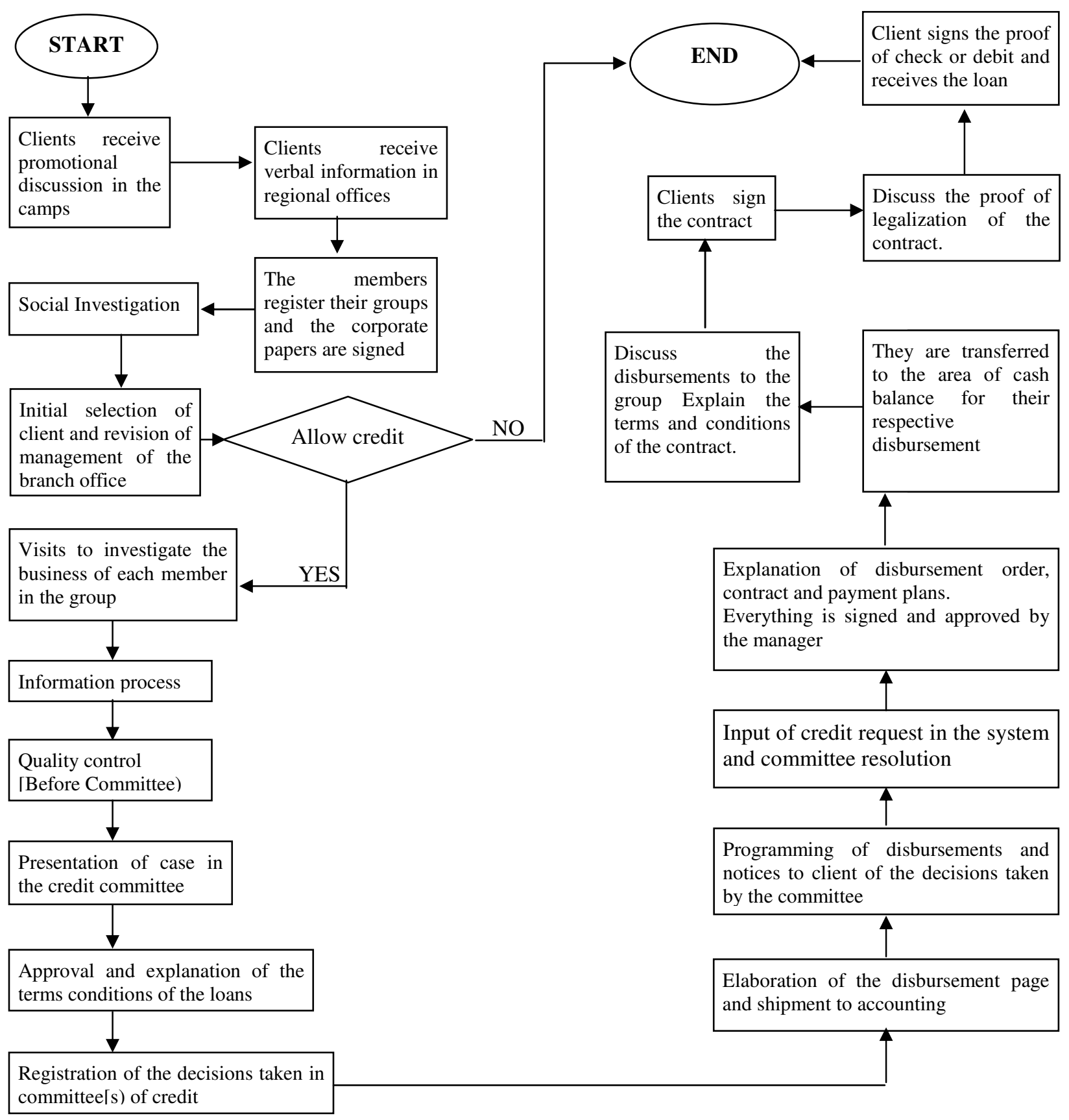

Figure 2. Business Process-Flowchart for the Allocation of an Urban Solidarity Credit

\section{CONCLUSIONS}

The Microfinance market has been growing rapidly in many developing countries. Bolivia, Peru, Brazil, Indonesia [5], Sri Lanka [6], the Philippines [8], and several African countries have made great strides in poverty alleviation by using microfinance to provide credit to the working poor. In some cases, there is significant government involvement, as in Sri Lanka and Indonesia, not always with positive results. In other cases, non-governmental organizations provided the leadership in moving forward with this well-respected form of poverty alleviation. In all cases, however, there is no substitute for professional financial management of the operation. Too often this aspect has not been carefully addressed. 
FDL is clearly a model operation both in Nicaragua and for the rest of Central America. This paper has identified the transparency with which the MFI is operated. The researchers have observed that those organizations that operate openly and whose Board of Directors are responsible and honest individuals are likely to continue to operate successfully, whereas the failure rate of improperly run MFIs grows each day.

As The Grameen Bank [7] demonstrated, innovation is an important aspect of MFIs. FDL has attempted to do this by loaning equipment to farmers in order to get them started. As in most cases, the repayment rate is above $95 \%$, and FDL is well within those parameters.

\section{REFERENCES}

1. FDL Annual Memory for 2004. FDL publication.

2. FDL Website, http://www.fdl.org.ni

3. The MIX Market Microfinance, http://www.mixmarket.org/en/demand/demand.s how.profile.asp?ett $=1064$

4. Personal Interviews on site.

5. Afwan, I. \& Charitonenko, S. (November, 2003). Commercialization of Microfinance: Indonesia. Manila, Philippines: Asian Development Bank.

6. Charitonenko, S. \& de Silva, D. (May 2002). Commercialization of Microfinance: Sri Lanka. Manila, Philippines: Asian Development Bank.

7. Grameen Bank. (2004). http://www.grameeninfo.org/

8. Charitonenko, S. (May 2002). Commercialization of Microfinance: The Philippines. Manila, Philippines: Asian Development Bank. 